\title{
Stakeholder Perspectives on Strategies that can Improve Student Performance in the School-Leaving Examinations in Lesotho
}

\author{
Mapheleba Lekhetho \\ College of Education, University of South Africa \\ Email: lekhem@unisa.ac.za
}

\section{Doi:10.5901/mjss.2013.v4n3p85}

\begin{abstract}
Despite the endless efforts by the Lesotho government and various stakeholders to improve student outcomes in secondary schools, particularly in the school-leaving examinations, the failure rate remains stubbornly high, resulting in high wastage rate. The study adopted a quantitative approach, using questionnaires and semi-structured interviews to gather data from 808 participants who included students, teachers, principals, school board members, school inspectors and education secretaries on the strategies that can be used to improve student performance in the school-leaving examinations. Simple descriptive statistics, mainly frequency counts and percentages are used to report the results. To improve academic performance the respondents suggested that there should be collaborative determination of teachers and students, a culture of speaking English at school, regular attendance of classes by teachers, the principal's purposeful leadership and decisiveness in maintaining order and discipline, and student selectivity to ensure that good students are selected at entry levels.
\end{abstract}

Keywords: Academic Performance, Effectiveness, Efficiency, Admission Policy.

\section{Introduction}

Lesotho education system is often criticised as inefficient, characterised by high rates of failure and dropout. Failure rate is particularly high in the school-leaving Cambridge Overseas School Certificate (COSC) examinations. For example, in 2012 the pass rate stood at 55.4 percent with only around 15 percent who qualified for direct university entrance (Examinations Council of Lesotho [ECOL] 2013). Some of the reasons for this low pass rate include: poor quality of primary education, often associated with low quality of primary school teachers, weak school management, insufficient resources, acute poverty, lack of teacher commitment, and inadequate support from the Ministry of Education (Lekhetho, 2013). Harris \& Chapman (2004) rightly note that despite sustained and well-intentioned efforts through targeted resources and strategic support, performance in schools in challenging circumstances remain stubbornly low. To stem the high failure rate in COSC, the government is currently in the process of working towards wholesale localization of the O'Levels by 2015 (ECOL, 2013). This study explores the strategies that can be used to improve student achievement in Lesotho secondary schools.

In recent years there has been growing interest among educational researchers in the twin fields of school effectiveness and school improvement, precipitated by the quest to investigate the factors that account for variances in academic performance between students and schools. The educational community has been concerned with the question of why schools with initially comparable inputs and student intakes differed in the extent to which they performed in the national examinations. Wilson and Fergus (1988) state that over the years, under the rubric of the Effective-Schools Research Movement, schools have been attempting to answer the question: who should be blamed for the failure of students in examinations? In trying to answer this question, principals, teachers, students and parents have been blamed (Wilson \& Fergus, 1988), and thus considered to be the units of analysis.

\section{Literature review}

This section explores different theoretical perspectives and views on school improvement. It first looks at the concepts of effectiveness and efficiency, which are central to understanding to school improvement process. 


\subsection{What is school effectiveness?}

Bennett (1997) argues that effectiveness measures how well the desired outcomes have been achieved when compared with the initial aims or intentions. For Creemers et al. (2007) effectiveness is concerned with the answers to the question, "Does the school achieve better student outcomes?" Lenkeit (2013) corroborates that Educational Effectiveness Research (EER) is concerned with the effects that classroom and school practices and policies have on student achievement. Stoll (1996) defines school effectiveness as the capacity of the school to maximise its functions, productivity, or the outcomes when given a fixed amount of inputs. In this sense, a school is judged effective if it enhances not only student productivity, but also teacher productivity. Dimmock (2000) maintains that effective schools are effective for all their students regardless of gender, ethnicity, ability, age or prior achievement. Thus, an effective school is one that provides effective teaching, creates enabling conditions to optimise student learning, and increases the chances of all its students to succeed academically. Moreover, the effectiveness of a school could be judged by its ability to inculcate social values, such as social harmony or good citizenship, democratic principles and humaneness in its students. Bennett (1997) argues that if one intended to achieve improved results and succeeded in that action, then the action or factors that helped to improve the results "would be effective against that goal." Effectiveness is thus concerned with the action or the question of "how" the work is done.

The concept effectiveness is related to efficiency to the extent that in casual talk some lay people use the two interchangeably, although they differ. According to Sota (2013) efficiency refers to a ratio between the inputs invested in education such as financial resources, time, personnel and other resources, and the outputs or results. UNESCO (2013) differentiates between internal efficiency and external efficiency thus: "internal efficiency measures the output and outcome of the education system while external efficiency measures the extent to which the competencies acquired in school translate into private and social benefits". Windham (1988) maintains that efficiency would exist where "the value of all outputs is maximized for a given cost of all inputs or where the cost of all inputs is minimized for a given value of all inputs." Thus, a school could be considered to be efficient if the inputs, such as classrooms, physical facilities, equipment and teachers' salaries are not increased but the examination results improve. School effectiveness is related to school improvement, discussed below, which focuses on the process of going about change in order to enhance student outcomes.

\subsection{School improvement: some factors that affect student achievement}

In order raise student achievement levels, schools should engage in deliberate actions to achieve this objective. Creemers et al. (2007) define school improvement as planned educational change that enhances student learning outcomes as well as the school's capacity for managing change. This definition highlights that school improvement is not an accidental event, but a planned action or deliberate interventions intended to improve student learning outcomes through a well-functioning school. Some of the key correlates of effective schools or factors that can improve student outcomes are discussed below.

\subsubsection{A focus on teaching and learning}

The first assumption of school effectiveness is that the core business of schools is teaching and learning, and, as such, the quality of a school is best judged by the quality of teaching and learning (Dimmock, 2000; Kuphe et al., 2013). Other aspects such as principal leadership are considered supportive and secondary in importance by comparison (Day et al., 2009). Purkey \& Smith (1985) emphasise that school success is measured by how well a learner masters the skills or knowledge of the subject. According to them, to be successful, schools need to concentrate on the academic outcomes, and other activities should be planned around this focal point. In a case study of a successful elementary school in Los Angeles, Beck \& Murphy (1998) found that there was a learning imperative at the school. This implies that the school regarded its fundamental goal as teaching and learning, which formed the nucleus of its activities and permeated the entire school culture.

In a study of top-performing school systems, McKinsey \& Company (2007) established that they focus mainly on improving instruction because of its direct impact on increasing student achievement. They do the following three important things right. Firstly, they recruit the right people to become teachers by making entry into teacher training highly selective (the quality of an education system cannot exceed the quality of its teachers). In this sense, the generally poor academic performance in Lesotho schools could be linked to low admission requirements into the initial teacher training 
programmes, especially in the primary school teaching phase. Secondly, they develop those people into effective teachers or 'instructors' (the only way to improve outcomes is to improve instruction). Thirdly, they put in place systems and support to ensure that every child benefits from excellent instruction (the only way for the system to reach the highest performance is to raise the standard of every student) (McKinsey \& Company, 2007).

\subsubsection{Facilities, equipment and educational materials}

The availability of basic facilities, such as self-contained classrooms, laboratories, audio-visual aids and equipment in schools is still a problem in most developing countries (Windham, 1988). Breton (2013) observes that in the aftermath of the financial crisis of 2008, resources are scarce, and many governments are seeking to cut public expenditures on programmes that do not yield significant returns. Due to favourable accessibility, and high population density, the urban schools in Lesotho, have a relatively better supply of facilities, textbooks and equipment vis-à-vis those in the rural areas. Well-maintained facilities provide a learning-conducive environment requisite for effective learning and textbooks are the indispensable primary essentials needed for successful academic learning. Heneveld (1994) holds that parents do not want to send their children to dysfunctional schools where buildings and equipment are dilapidated as these would have a negative effect on their learning.

\subsubsection{Support and pressure from external agencies}

Support from the Ministry of Education is essential to the enhancement of school management, school change and staff stability (Purkey \& Smith, 1985). SREB (2010) concurs that the Ministry of Education at national and district levels should work with principals and school leadership teams to create a school environment that improves student engagement and learning. The support the school receives from the external agencies is not only crucial to the functioning of the whole school, but also to the running of a department. Harris (2000) contends that the external expertise and support that the department receives from external agencies can help to improve teaching practices and offer alternative ways of teaching and learning. He maintains that isolation and lack of external support can be detrimental to the functioning of a school or a department. It is argued that to increase teacher productivity and learner achievement, schools should maintain open communication networks and sound relations with the external agencies.

Furthermore, Reezigt \& Creemers (2005) note that in practice schools need external pressure to start improving. They identify four types of pressure, namely market mechanisms, external evaluation and accountability, external agents and participation of society and societal changes. Market mechanisms - concerns the need for competition between schools, which leads to consumers (parents) being better informed about quality and school choice or freedom to choose a good school in the 'market' (Reezigt \& Creemers, 2005). External evaluation and accountability - relates to assessment of student outcomes with a national validated test, which will help to hold schools accountable. Also, when the results are published, schools are indirectly 'forced' to improve performance. In Lesotho, since 2006 there are annual district-based top achievers' awards ceremonies to honour students, schools and teachers who performed well in the public examinations the previous year. To a large extent, these ceremonies exert pressure on teachers and students to work harder. External agents refer to school inspectors, consultants and researchers who provide expertise and may exert pressure on schools to improve. Participation of society and societal changes also exert pressure on schools because the curriculum offered embraces the needs and aspirations of society, usually embedded in the educational policies.

\subsubsection{Strong school leadership}

Barker (2001) studied what constitutes an effective school and the factors that account for the between-school variances in academic achievement and established that strong leadership is a key correlate of effective schools. Hofman (1995) describes strong, educationally oriented leadership by the principal as one of the factors of effective management because it can help to strengthen cohesion amongst teachers and stimulate their commitment to their professional work. Lack of strong leadership by the principal could render school activities uncoordinated. Mortimore et al. (1993) conclude that purposeful leadership of the staff by the principal is strategic and goal-oriented, where the principal should have a clear purpose or vision stemming from the school mission. An effective, goal-oriented leader should be actively involved in school-wide activities, such as planning, organising and curricular matters.

Dantley (1990) maintains that effective leadership requires that the principal be instrumental in setting the ethos of the school, adroit in making decisions on instructional strategies, and efficient in organising and distributing resources. 
Effective principals are key for creating a task-relevant climate within the school, supporting the work of teachers, motivating students and sustaining their interest. Day et al (2009) observe that as a school influence on learning, effective school leadership only comes second to classroom teaching. Furthermore, Sergiovanni (1998) submits that the goal of better results for all learners will not be achieved unless schools embrace "pedagogical leadership." He proposes that a starting point for improving the academic results in schools is to develop social and academic capital for learners and professional capital for teachers. According to him, capital is the value of something, which when properly invested, produces more of what is invested, thus increasing the overall value. Pedagogical leadership can be supported by providing capital to enhance student learning and development, teacher training, teacher efficiency and classroom effectiveness (Sergiovanni, 1998). He adds that schools develop academic capital by becoming focused communities that cultivate a strong culture of teaching and learning.

\subsubsection{Teacher professional development}

According to Postholm (2012), teacher professional development means teachers' learning, how they learn to learn, and how they apply new knowledge to support student learning. The most important factors required to attain good results are the school's capacity to support professional learning and the cooperation of teachers in educational activities (Postholm, 2012). SREB (2010) aptly asserts that low-performing schools are not likely to turn around unless teachers in those schools have adequate opportunities to learn and implement effective practices that engage students in challenging learning. Reynolds and Teddlie (2000) point out that recent studies indicate that school-based and work-relevant staff development programmes are central to improving schools. However, it remains the responsibility of the principal and the heads of departments to organise school-based staff development programmes for teachers. In many secondary schools in Lesotho, there are currently no school-based staff development programmes that deal with the professional needs of teachers. Most of the staff development programmes are organised by external agencies, mainly the Ministry of Education. Reynolds \& Teddlie (2000) contend that a one-off presentation by an expert coming from outside the school is not likely to have much impact or to improve the practice.

\subsubsection{Teaching stability and consistency}

The stability of the administrative staff and the teaching force at school are considered to impact significantly on improving the effectiveness of the school. This implies that the lesser the staff turnover, the more amenable to improvement the school should become. In this regard, Heneveld (1994) argues that stability implies that the majority of teachers have taught together in the same school for a considerable length of time, and that low teacher turnover is generally an indicator of positive teacher morale or relative satisfaction with the school conditions. The school principal should play a key role in setting a positive school ethos that ensures staff retention.

Every effort should be made to encourage stability and continuity at school as it promotes staff cohesion and controls staff turnover (Cohn \& Rossmiller, 1987; Mortimore et al., 1993). To some extent, this lies within the professional capacity of principals as they can forge a convivial, task-relevant work environment that nurtures the professional growth of teachers, which has staff retention effect. Purkey \& Smith (1985) maintain that frequent "transfers are likely to retard ... the growth of a coherent and ongoing school personality, especially in early phases of the change process." A further point to consider is to avoid the change of a subject teacher during the course of the year as this may have an adverse effect on learners (Mortimore et al., 1993). If a change occurs during the course of the year, there should be a smooth handover to the next teacher in order to mitigate the negative impact on learners.

\subsubsection{School culture}

According to Castetter \& Young (2000), culture is a set of interrelated behaviours, values, norms, expectations and ideals shared by members of a group of an organisation. Culture also dictates how people should behave, treat one another and non-members, and act in given situations (Seyfarth 1999, Dimmock, 2000). Thus, culture could be regarded as glue that holds members of an organisation together and provides a working milieu amenable to productivity. Owens (1991) argues that organisational culture can be regarded as solutions to internal and external problems that have worked reliably for a long time for a group, and are therefore taught to new members of an organisation as the correct way to deal with those problems. According to Purkey \& Smith (1985:356), "Student academic performance is strongly affected by school culture." Hence, Macneil (2009) emphasise that principals should pay attention to culture because their impact on 
learning is not direct, but mediated through the climate and culture of the school. Thus they stress that principals are responsible for establishing a pervasive culture of teaching and learning.

\section{Statement of the problem}

Lesotho has been faced with a challenge of poor student performance in the school-leaving, Cambridge Overseas School Certificate examinations for many years characterized by a disproportionately large number of students who do not meet the admission requirements for tertiary education. Since it is a poor country with very limited economic opportunities, the school-leaving examinations determine the life chances or fate of a student beyond secondary education. Against this background, this study endeavours to explore empirically-grounded strategies that could be used to improve student achievement in the school-leaving examinations and improve the overall effectiveness of secondary schools in Lesotho as proposed by the research participants. Thus the study seeks to answer the following main research question:

What strategies could be used to improve the poor student performance in the school-leaving, examinations in Lesotho?

\section{Methodology}

In this study, a survey was used because the problem of ineffective schools in Lesotho is widespread and multidimensional, and as such, it was deemed proper to get a balanced view from different stakeholders about the strategies that can be employed to improve student performance in the COSC examinations. Schools in this study were spread across the three geographical areas of the Maseru district, namely rural, peri-urban and urban areas. Hence, questionnaires were found to be more appropriate to collect data from a diverse target population, namely students, teachers, deputy principals, school board members and school inspectors. Additionally, a semi-structured interview was used to gather information from five education secretaries representing major denominational proprietors because they were few and rich in information required.

Quantitative research explains phenomenon by collecting numerical data and analysing it using mathematically based methods, particularly statistics (McMillan \& Schumacher, 2010). The quantitative method is regarded as scientific and objective because it uses the scientific principles from the design of questionnaires, the selection of the study samples, and the presentation of the results. The qualitative method, on the other hand, provides a vivid picture of the life-world of the participants, because they provide in-depth responses to open-ended questions in semi-structured or unstructured interviews.

\subsection{Sample selection and sampling techniques}

In this study, 25 high schools in the district of Maseru were selected by stratified random sampling to ensure that they were representative of the school proprietors, location with regard to rural, urban and peri-urban areas, and the level of school effectiveness using the COSC pass lists of the past five years to classify schools into high-, average- and lowperforming schools. After selecting schools by a stratified sampling method, the participants were selected by random sampling to guarantee every member of the population an equal chance of being selected (Creswell, 2009). In order to obtain a wider view on strategies that improve student achievement, 45 additional high schools in the districts of Leribe, Berea, Mafeteng, Mohale's Hoek and Qacha's Nek were purposively selected for the principal, deputy principal and school board member samples only. Table 2 reflects the number of questionnaires distributed and those that were returned, and interviews conducted with five education secretaries.

Table 1: Research participants

\begin{tabular}{|l|c|c|c|}
\hline Respondent group & Planned & Returned & $\%$ \\
\hline Form E students & 625 & 575 & 92 \\
\hline Teachers & 250 & 110 & 44 \\
\hline Deputy principals & 70 & 40 & 57.1 \\
\hline Principals & 70 & 43 & 61.4 \\
\hline School board members & 70 & 17 & 24.3 \\
\hline School inspectors & 20 & 12 & 60 \\
\hline Education secretaries & 5 & 5 & 100 \\
\hline Total & $\mathbf{1 1 1 0}$ & $\mathbf{8 0 8}$ & $\mathbf{7 3}$ \\
\hline
\end{tabular}




\subsection{Research ethics and principles}

During field work, the researcher carefully adhered to the principles of research by disclosing fully to the research participants, what the purpose of the study was, and clarifying that they were not obliged to take part in the study. Before administering the instrument, the researcher sought informed consent from the participants, and assured them that the information they provided would be treated confidentially and anonymously to protect their identity (Cohen et al., 2007). The researcher also emphasized that participants were free to withdraw from the study if they felt that the questions interfered with their right to privacy or created some kind of discomfort (Cohen et al., 2007). To ensure that there was clarity in the questionnaires, the researcher answered all the questions that sought clarification.

\section{Data analysis}

Data were 'cleaned' by identifying and eliminating all errors deriving from the questions that respondents misinterpreted including other associated inaccuracies. Bryan (2012) refers to this process as managing data, to establish if there are any flaws. This was followed by data coding and data reduction, which refers to translating both closed and open-ended answers into numbers or segments in order to develop the meaning of each segment (Creswell 2009). As Bryan (2012) notes, unless data is reduced it will be almost impossible for the researcher to interpret the material. Descriptive statistics were used to summarise, organise and reduce large numbers of observations (McMillan \& Schumacher, 2010). Openended responses or textual data were coded to facilitate the process of identifying recurring themes and translating data into frequency counts.

Due to time, a pre-test could not be conducted to the check validity and reliability of the research instrument. However, this situation was circumvented by the meticulous construction of questionnaires and the interview schedule. This involved eliminating ambiguity and repetition, proofreading them and passing them to the language editor and two experienced researchers for expert advice. After making the necessary changes as advised, the instruments were administered.

\section{Results and discussion}

In order to get an overall picture of how most stakeholders viewed the general performance of their schools, participants were asked to rate the performance of their school in COSC examinations on a Likert-type scale question with the following options provided: (a) excellent, (b) very good, (c) good, (d) fair, (e) poor, (f) very poor. Overall, most of them rated it as average, followed by those who rated it as poor. Subsequently, they were asked to propose strategies that can improve student achievement. Their suggested strategies are discussed below.

\section{Strategies for improving performance in COSC examinations}

- Collaborative determination and hard work by students and teachers;

- A culture of speaking English at school;

- Extended and productive study;

- Recruitment of qualified, stable and dedicated teachers;

- Teachers should attend classes regularly;

- Firm and effective school leadership;

- An adequate provision of facilities;

- A good admission policy; and

- Intra-school and interschool academic competitions.

\subsection{Collaborative determination and hard work by students and teachers}

A substantial number of student respondents, 197 (42.8\%), suggested that hard work or the sustained collaborative determination of students and teachers is a key factor that can improve students' academic performance. On the other hand, this variable was mentioned by 34 (35\%) teachers, 11 (26\%) principals, 14 (38\%) deputy principals, 1 (6\%) school board member and 2 (16.7\%) school inspectors. This finding reveals that, generally, students prefer to work collaboratively with their teachers. They felt that a one-way effort or commitment by students would not be sufficient in 
improving student outcomes. Muijs et al (2004) concur that it is possible for schools in difficult circumstances to "buck the trend" and add value to student learning and achievement, but to achieve that, they should redouble their efforts and exceed what could be termed "normal efforts". Similarly, McKinsey \& Company (2010) established during the interviews with leaders of improving school systems that creating improvement required a lot of discipline and constant forward momentum.

\subsection{A culture of speaking English at school}

Some 114 (25\%) student respondents stated that the performance of their schools could improve if students could speak English consistently at school. Some emphasised that there should be a strong culture of speaking English by both students and teachers in schools, and that teachers should be exemplary in this regard. In contrast, this was suggested by a small fraction of other respondents; only $10(10 \%)$ teachers, 4 (10\%) principals, $5(14 \%)$ deputy principals, 5 (29.4\%) school board members, $3(25 \%)$ inspectors and $1(20 \%)$ Education Secretary. Some respondents stated that speaking English at school is indispensable for improving the students' academic performance because all subjects, except Sesotho (vernacular), are taught in English. A lack of proficiency in written and spoken English was seen as a serious handicap that hinders the process of effective student learning, and the root cause of their weakness in other subjects.

Some respondents cited a lack of a reading culture amongst the students as a factor that undermines their acquisition and mastery of English language. The cause of this could be a dearth of appropriate reading materials in the country, written in English that is accessible to students. One education secretary indicated that Basotho as a nation, including teachers lack a reading culture, and this has a ripple effect on students. He put it thus: "As Basotho, we are not a reading nation, but a talking nation." Furthermore, one school inspector accentuated that the students' proficiency in English is central to successful learning, and suggested that students should be immersed in English at school. He was concerned that the teaching or learning of English at school is predominantly classroom-bound, restricted to 40-minute periods only. In his school effectiveness study in South Africa, Taylor (2011) recommends that a pervasive verbal culture in schools should be replaced by increased tempo of reading and writing. He recommends: "Children need to read and write every day in every subject. At least once a week such writing should consist of extended essays of a descriptive, expressive or analytical kind".

\subsection{Extended and productive study}

Fifty-four (12\%) student respondents suggested that to improve academic performance, study time should be extended and supervised so that it could become productive. This factor was however, found to be less important by other respondent groups, as only $4(10 \%)$ principals, 1 (3\%) deputy principal and 2 (13\%) school board members mentioned it. Most students who suggested a need for an effective study, expressed discontent with the way study time is abused by some disruptive students, and some teachers who used it for remedial work or sport in some cases. Some students indicated that they would prefer to have the study conducted in the morning when their minds were still active rather than after school when they were already worn out. While a substantial number of student respondents suggested that an extended study would be ideal, a few boarders remarked that they were sometimes subjected to long periods of study, which tired them out. Thus, to ensure that study is productive, it would be sensible to have it properly timed and supervised.

\subsection{Recruitment of qualified, stable and dedicated teachers}

Fifty-one (11\%) student respondents reported that one of the factors that could improve their schools' performance would be the recruitment of qualified, stable and dedicated teachers. This was mostly reported by students in rural schools, which often experience a shortage and a high turnover of teachers, especially those of mathematics and science subjects. On the other hand, this was reported by $7(7 \%)$ teachers, $23(55 \%)$ principals, $5(14 \%)$ deputy principals, 5 (29.4\%) school board members, 5 (41.7\%) inspectors and 3 (60\%) education secretaries. According to Taylor (2011), unless teachers are properly taught, they would not be able to pass on the teaching. Similarly, Sanders and Rivers (1996) confirm that "... the influence of teachers is the single most important factor in determining student's achievement". This is because "teachers are considered an essential lever of change, because change is explicit in their classrooms and daily practice...." (Reezigt \& Creemers, 2005). They also indicate that school improvement efforts would be ineffectual if there is no stability in the staff. 
A large proportion of principals, $23(55 \%)$, more than any other school-level respondent group, considered the availability of well-qualified, stable and dedicated teachers to be another factor that could improve the academic performance of their schools. This is possibly because, as the day-to-day executive managers of schools, they see the negative impact of unqualified, unstable and uncommitted teachers on the functioning of schools and student learning. Some principals expressed concern at the high teacher turnover in their schools, and said that it was not only caused by teachers who transferred to other schools or changed jobs, but also by those who went for further studies, still retaining their posts as the contractual employees of their schools.

\subsection{Teachers should attend classes regularly}

Some $46(10 \%)$ student respondents suggested that to improve academic performance, teachers should attend classes regularly. This was cited by $18(19 \%)$ teachers, $2(5 \%)$ principals, $16(43 \%)$ deputy principals, $8(50 \%)$ school board members and 7 (70\%) inspectors. They indicated that the regular attendance of classes by teachers could develop staff cohesion and a positive attitude for improving performance of their schools. The fact that teacher commitment although couched in different terms recurs here shows how critical it is to improving student achievement. This signals that teacher absenteeism and tardiness are still common in some schools. Shannon and Bylsma (2007) concur that "establishing a focus on learning is an important first step for improving schools". It is therefore, important that school activities are planned around it to make sure that it does not suffer at the expense of extracurricular activities.

\subsection{Firm and effective school leadership}

Overall, a few respondents identified firm and effective leadership of the principal as an important factor that could contribute towards improving the academic performance of their schools. This factor was mentioned by only $42(9 \%)$ students, $5(5 \%)$ teachers, 2 (5\%) principals, $6(16 \%)$ deputy principals, $1(6 \%)$ school board member, $3(20 \%)$ inspectors and $2(40 \%)$ education secretaries. The student respondents emphasised that their principals needed to be dedicated to their work, and to be strict with both students and teachers, and ensure that teachers do their professional work diligently, and that students study hard. This is in line with Sergiovanni's (1990) conceptualisation of value-added leadership, which he reckons as a powerful force of leadership by the principal that can stimulate the drive and commitments of both teachers and students more than the use of authority or control.

\subsection{An adequate provision of facilities}

Contrary to expectation, only $25(5.4 \%)$ student respondents indicated that an adequate provision of facilities such as libraries, laboratories and classrooms, is important for improving student achievement. However, this factor was mentioned by $22(23 \%)$ teachers, 14 (33\%) principals, 14 (38\%) deputy principals, $11(64.7 \%)$ school board members, 3 $(30 \%)$ inspectors and $4(80 \%)$ education secretaries. It is discernible from this dichotomy of perceptions between students and other respondents on this issue that the students considered student and teacher productivity more important, while other respondents considered an adequate supply of resources to be vital for improving performance, possibly because as professionals, they see the negative impact of lack of resources on teaching and learning.

\subsection{A good admission policy}

Relatively speaking, a few student respondents, $15(3 \%)$, cited good admission policy or student selectivity as an important factor that can improve student achievement. On the other hand, this was reported by $15(16 \%)$ teachers, 5 (12\%) principals, 12 (32\%) deputy principals, 1 (6\%) school board member. Some students, particularly the high achievers from the high-performing schools, suggested that their schools should be strict in promoting students from one class to the next. They suggested that their schools should abolish an automatic promotion system, where all students are promoted from one class to the next at the end of the school year, regardless of whether they passed or not. They stressed that student promotion should be based on merit only. Some student respondents suggested increasing the pass mark from $40 \%$ to $50 \%$ as another strategy that could improve academic performance of their schools. One teacher corroborated thus: "We can increase the promotion mark to 50\%, which must include a pass in both English and mathematics. In that way, we can improve our Junior Certificate and COSC results, and stand a better chance of getting applications from good students - students with first and second class passes." 
The teacher respondents emphasised that their principals needed to be selective when admitting applicants to Form A, and to stick to the predetermined admission policies of their schools. They also stressed that their schools should stick to the established standards when promoting students to senior classes. However, the question remains: how can the principals stick to the strict admission policies when there are more low calibre candidates who complete primary and junior secondary school? For low-performing schools, student selectivity poses a challenge to principals of having to harmonise two contradictory goals of striving to improve the poor academic results, whilst they are also struggling to meet the enrolment requirement of a minimum of 400 students per high school, stipulated by the Ministry of Education.

\subsection{Intra-school and interschool academic competitions}

Fifty-two (11\%) student respondents, 15 (37\%) principals and $5(13 \%)$ deputy principals suggested that there should be intra-school and interschool competitions in academic activities, such as debates and quizzes, in order to promote communication and problem-solving skills in students. They suggested that clubs for subjects such as science, mathematics and English should be formed in order to enhance the students' cognitive abilities and appreciation, and to heighten the spirit of competition amongst students. It would appear that students have a strong predilection to learn by competition, either to compete with one another within the same school or with their contemporaries in other schools. Verhoeff (1997) agrees that children spontaneously seek competition with others to compare themselves with their peers in every way, be it running, wrestling and various other games, which he says is "beneficial to a child's development."

\section{Conclusion}

From the analysis of the findings, collaborative commitment of teachers and students was seen as a key strategy that can improve schools' academic performance. The commitment of one group without the corresponding effort by the other was considered to be ineffectual. In particular, the student respondents suggested that teachers should attend classes regularly and teach effectively, which signals that teacher absenteeism is common in some schools. To counter English language deficiency among students, the respondents recommended that schools should immerse students in spoken and written English so that they can acquire adequate competency. High teacher turnover, especially in the rural schools was identified as a factor that disrupts student learning; hence it was suggested that the recruitment of qualified and stable teachers, particularly of mathematics and science subjects can improve student outcomes. Purposeful leadership of the principal and decisiveness in ensuring that there is order and discipline at school, and that teachers attend classes regularly, was proposed mostly by the student respondents. Finally, student selectivity or a selection of good applicants into junior and senior secondary school levels was identified predominantly by teachers, as another strategy that can raise the results of their schools in the school-leaving examinations.

\section{References}

Barker, B. (2001). Do Leaders Matter? Educational Review, 53(1), 65-76.

Beck, L.G. \& Murphy, J. (1998). Site-based Management and School Success: Untangling the Variables. School Effectiveness and School Improvement, 9(4), 358-385.

Bennet, N. (1997). Analysing Management for Personal Development: Theory and Practice. In L. Kydd, M. Crawford. \& C. Riches (Eds), Professional Development for Educational Management (pp. 60-73). Buckingham: Open University Press.

Breton, T.R. (2013). The role of education in economic growth: theory, history and current returns. Educational Research, 55(2), $121-138$.

Bryan A. (2012). Social research methods. (4th ed.). Oxford: Oxford University Press.

Castetter, W.B. \& Young, I.P. (2000). The Human Resource Function in Educational Administration. (7th ed.). London: Prentice-Hall International.

Cohen, L., Manion, L. \& Morrison, K. (2007). Research Methods in Education (6th ed.). London: Routledge Falmer.

Cohn, E. and Rossmiller, R.D. (1987). Research on Effective schools: Implications for less developed countries. Comparative Education Review, 31(3), 377-399.

Creemers BPM, Stoll L and Reezigt G. (2007). Effective school improvement - ingredients for success: The results of an international comparative study of best practice case studies. T. Townsend (Ed.). International Handbook of school effectiveness and improvement (pp. 825-838). Dordrecht, The Netherlands: Springer.

Creswell JW (2009). Research Design: Qualitative, Quantitative, and Mixed Methods Approaches. (3 $3^{\text {rd }}$ ed.). Thousand Oaks, California: Sage.

Dantley, M.E. (1990). The Ineffectiveness of Effective Schools Leadership: An Analysis of the Effective Schools Movement from a Critical Perspective. Journal of Negro Education, 59(4), 585-598.

Day C, Sammons P, Hopkins D, Harris A, Leithwood K, Gu Q, Brown E, Ahtaridou E and Kingston A (2009). The impact of school leadership on pupil outcomes: Final Report. Nottingham: university of Nottingham Press and Sage.

Dimmock, C. (2000). Designing the Learning-Centred School: A Cross-Cultural Perspective. London: Falmer Press. 
ECOL. (2013). About ECOL. [Online] Available: http://www.ecol.org.ls/about-ecol (June 18, 2013).

Examinations Council of Lesotho. (2013). 2012 COSC Passlist. Maseru: ECOL.

Harris, A. (2000). Effective Leadership and Departmental Improvement. Westminster Studies in Education, 23:81-90.

Harris A \& Chapman C. (2004). Improving schools in difficult contexts: towards a differentiated approach. British Journal of Educational Studies, $52(4), 417-431$

Heneveld, W. (1994). Planning and Monitoring the Quality of Primary Education in sub-Saharan Africa. Washington, D.C.: The World Bank.

Hofman, W.H.A. (1995). Cross-level relationships within effective schools. School Effectiveness and School Improvement, 6(2),146-174.

Kuphe, C., Balkwill, K., Osman, R., \& Cameron, A. (2013). A needle haystack: a search for value for money in turn-around strategies for schools in difficult circumstances. Educational Research, 55(2), 165-179.

Lekhetho, M. (2013). Lesotho: Organization, structures and challenges. In: C Harber (Ed.): Education in Southern Africa. London: Bloomsbury Academic, (in press).

Lenkeit J (2013). Effectiveness measures for cross-sectional studies: a comparison of value-added models and contextualised attainment models. School Effectiveness and School Improvement, (24)1, 1-25

Macneil AJ, Prater DL and Busch S. (2009). The effect of school culture and climate on student achievement. International Journal of Leadership in Education, 12(1), 73-84

McKinsey \& Company. (2007). How the world's best-performing school systems come out on top. [Online] Available: http://mckinseyonsociety.com/how-the-worlds-best-performing-schools-come-out-on-top (June 29, 2013).

McKinsey \& Company. (2010). How the world's most improved school systems keep getting better. [Online] Available: http://mckinseyonsociety.com/how-the-worlds-most-improved-school-systems-keep-getting-better (June 29, 2013)

McMillan. J.H. \& Schumacher, S. (2010). Research in Education: Evidence-based Inquiry. (7th ed.). Boston: Pearson.

Mortimore, P., Sammons, P., Stoll, L. Lewis, D. and Ecob, R. (1993). Key Factors for Effective Junior Schooling. In M. Preedy (ed). Managing the Effective School. London: Chapman.

Muijs D, Harris A, Chapman C, Stoll L and Russ J (2004). Improving schools in socioeconomically disadvantaged areas - a review of research evidence. School effectiveness and school improvement, 15 (2), 149-175.

Owens R.G. (1991). Organizational Behaviour in Education. (4th ed.). Boston: Allyn \& Bacon.

Pennycuick, D. (1998). School Effectiveness in Developing Countries: A Summary of the Research Evidence. Unpublished research paper. Sussex: University of Sussex.

Postholm MB (2012). Teachers' professional development: a theoretical review. Educational Research, 54(4), 405-429

Reezigt GJ and Creemers BPM (2005). A comprehensive framework for effective school improvement. School Effectiveness and School Improvement, 16(4), 407-424.

Reynolds, D. and Teddlie, C. (2000). The Processes of School Effectiveness. In C. Teddlie and D. Reynolds (Eds). The International Handbook of School Effectiveness Research. London: Falmer Press.

Sergiovanni, T.J. (1998). Leadership as Pedagogy, Capital Development and School Effectiveness. International Journal of Leadership, 1(1), 3747.

Sergiovanni, T.J. (1990). Value-Added Leadership: How to Get Extraordinary Performance in Schools. San Diego. Harcourt Brace Jovanovich.

Seyfarth, J.T. (1999). The Principal: New Leadership for New Challenges. New Jersey: Prentice Hall.

Shannon GS and Bylsma P (2007). The Nine Characteristics of High-Performing Schools: A research-Based Resource for Schools and Districts to Assist with Improving Student Learning. (2nd ed.). Olympia, WA: OSPI.

Sota, Jani. (2013). Efficiency and effectiveness in pre-university in the optics of human capital theory. Mediterranean Journal of Social Sciences, $4(2), 71-79$

SREB (2010). The Three Essentials: Improving schools requires district vision, district and state support, and principal leadership. [Online] Available: http://www.wallacefoundation.org/knowledge-center/school-leadership/district-policy-and-practice/Documents /ThreeEssentials-to-Improving-Schools.pdf (June 29, 2013)

Stoll, L. (1996). Linking School Effectiveness and School improvement: Issues and Possibilities. Gray, J., Reynolds, D., Fitz-Gibbon, C. and Jesson, D. (eds). Merging Traditions: The Future of Research on School Effectiveness and School Improvement. London: Caswell.

Taylor N (2011). The National School Effectiveness Study (NSES): Summary for the synthesis report. Johannesburg: JET education services.

UNESCO (2013). System efficiency. [Online] Available: http://www.unesco.org/new/en/education/themes/strengthening-educationsystems/quality-framework/supporting-mechanisms/system-efficiency (June 27, 2013)

Verhoeff, Tom (1997). The Role of Competitions in Education. [Online] Available: http://olympiads.win.tue.nl/ioi/ioi97/ffutwrld /competit.html (June $28,2013)$

Wilson, C.D., \& Fergus, E.O. (1988). Combining Effective Schools and School Improvement Research Traditions for Achieving Equity-Based Education. Equity and Excellence, 24(1), 54-65. 